\title{
Heterogeneous selective synthesis of 1,2-dihydro-1,3,5-triazines from alcohols and amidines via $\mathrm{Cu} / \mathrm{OMS}$-2-catalyzed multistep oxidation
}

Xu Meng, ${ }^{\mathrm{a}}$ Xiuru Bi, ${ }^{\mathrm{a}}$ Yanmin Wang, ${ }^{\mathrm{a}}$ Gexin Chen, ${ }^{\mathrm{a}}$ Baohua Chen, ${ }^{\mathrm{b}}$ Zhenqiang Jing, ${ }^{\mathrm{c}}$ Peiqing $\mathrm{Zhao}^{\mathrm{a},{ }^{*}}$

a State Key Laboratory for Oxo Synthesis and Selective Oxidation, Suzhou Research Institute of LICP, Lanzhou Institute of Chemical Physics (LICP), Chinese Academy of Sciences, Lanzhou 730000, China. Fax: + 96931 8277008; Tel: + 86931 4968688; E-mail: zhaopq@licp.cas.cn

b State Key Laboratory of Applied Organic Chemistry, Lanzhou University, Lanzhou 730000, China

c Suzhou Institute of Nano-Tech and Nano-Bionic (SINANO), Chinese Academy of Sciences, Suzhou 215123, China

\begin{abstract}
Copper supported on octahedral manganese oxide molecular sieve (OMS-2) which was obtained via reducing $\mathrm{KMnO}_{4}$ by TBHP was prepared and found to be an efficient catalyst for the synthesis of 1,2-dihydro-1,3,5-triazines directly from alcohols and amidines in one-pot via multistep oxidation. The recyclable heterogeneous catalyst was characterized by BET, XRD, FTIR, TEM and SEM, and the catalytic system can tolerate a wide range of substrates under air with low catalyst loading of supported copper $(0.25 \mathrm{~mol} \%)$, employing OMS-2 as the electron-transfer mediator (ETM) and support.
\end{abstract}

Key word: heterogeneous catalysis, multistep oxidation, OMS-2, supported catalyst, triazine 


\section{Introduction}

In recent years, multistep catalytic oxidation using green oxidants, such as $\mathrm{O}_{2}$ and $\mathrm{H}_{2} \mathrm{O}_{2}$, has gained importance in organic synthesis and catalysis compared with direct oxidation using stoichiometric amounts of metallic oxidants because of environmental and economic factors.[1] In particular, Backväll group developed a series of $\mathrm{Pd} / \mathrm{BQ} / \mathrm{Fe}(\mathrm{Pc}) / \mathrm{O}_{2}$ system which can improve electron-transfer via decreasing the redox barriers between catalytic metals and oxidants by the use of electron-transfer mediator (ETM).[2-7] More recently, Sundén`group reported a multistep electron transfer NHC catalytic system which was able to selectively synthesize $\alpha, \beta$-unsaturated esters via the introduction of quinone and $\mathrm{Fe}(\mathrm{Pc})$ as ETMs.[8] In 2015, Largeron'group used copper as ETM to discover an $o$-iminoquinone-catalyzed multistep oxidation for the synthesis of benzimidazoles initiated by transamination process.[9,10] However, heterogeneous multistep catalytic oxidation is a more acceptable pathway compared with the aforementioned homogeneous counterparts, due to the ease in separation, recovery and recycling. Consequently, there is an incentive to develop a heterogeneous system able to catalyze the organic transformations by multistep oxidation with green oxidants by the use of recyclable catalysts.

As a part of our continuing efforts on heterogeneous synthesis, we have developed several systems for the heterocycles synthesis by employing a series of manganese oxide-supported copper (Cu/OMS-2) as catalysts and air as green oxidant.[11-13] In terms of catalytic mechanism, we envisaged the catalytic system combines two redox couples: supported $\mathrm{Cu}$ acts as catalytic component and is reoxidized by mixed valent OMS-2,[14-20] whereas support OMS-2 acts as ETM and is reoxidized by $\mathrm{O}_{2}$ (Scheme 1). In this way, the electrons in an oxidation transfer quickly from substrates to green oxidant via multistep oxidation generated by $\mathrm{Cu} / \mathrm{OMS}-2$, which can avoid unselective reactions. With this in mind, we envisioned the possibility of employing recyclable $\mathrm{Cu}$ /OMS-2-based materials to selectively synthesize important heterocycles, like polyfunctional 1,2-dihydro-1,3,5-triazines, starting 
from readily available substrates through multistep oxidation.

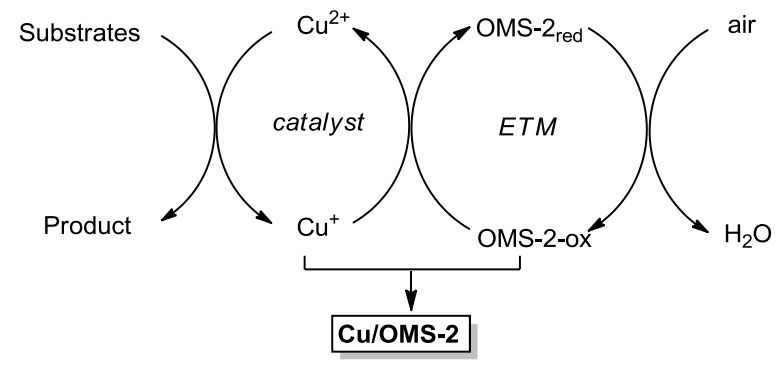

Scheme 1. Aerobic multistep oxidation using $\mathrm{Cu}$ as catalytic metal and OMS-2 as ETM and support.

Polyfunctional dihydro-1,3,5-triazine is one of the most important nitrogen-containing heterocycles because of their various biological activities, such as antibacterial, antimalarial, antitumor and anti-inflammatory properties.[21] Furthermore, dihydrotriazine derivatives are applied in commercialized herbicides, corrosion inhibitors and insecticides.[22] However, the synthetic methods for polyfunctional 1,2-dihydro-1,3,5-triazines are limited.[23,24] Herein, we would like to disclose that OMS-2 was prepared for the first time through the reduction of $\mathrm{KMnO}_{4}$ by the low loading of TBHP and employed as support and ETM in supported catalyst $\mathrm{Cu} / \mathrm{OMS}-2$. In the presence of $\mathrm{Cu} / \mathrm{OMS}-2$, polyfunctional 1,2-dihydro-1,3,5-triazines were synthesized in a highly selective pathway directly from alcohols and $\mathrm{N}$-arylamidines in one-pot via multistep oxidation (Scheme 2).

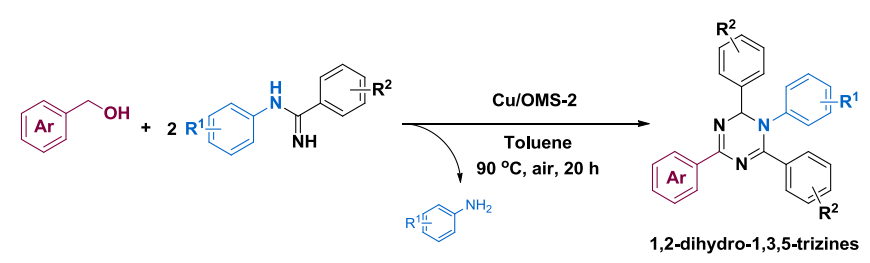

Scheme 2. Access to 1,2-dihydro-1,3,5-triazines catalyzed by Cu/OMS-2.

\section{Experimental}

\subsection{Catalyst preparation}


$1 \mathrm{~mL}$ of TBHP (70\% water solution) was added to a buffer solution consisting of $2.5 \mathrm{~mL}$ of acetic acid and $5 \mathrm{~g}$ of KOAc in $20 \mathrm{~mL}$ of deionized water. A solution of $3.25 \mathrm{~g}$ of $\mathrm{KMnO}_{4}$ in $75 \mathrm{~mL}$ of deionized water was then added dropwise to the above mixture while stirring. The resulting solution was refluxed at $100{ }^{\circ} \mathrm{C}$ for $10 \mathrm{~h}$, and the product OMS-2 was filtered, washed, dried in air at $80{ }^{\circ} \mathrm{C}$ overnight to remove water and dried at $120{ }^{\circ} \mathrm{C}$ for $2 \mathrm{~h}$. Next, Support OMS-2 (2 g) was added to a $50 \mathrm{~mL}$ round-bottom flask. A solution of $\mathrm{Cu}\left(\mathrm{NO}_{3}\right)_{2} \cdot 3 \mathrm{H}_{2} \mathrm{O}(0.05 \mathrm{~g})$ in deionized water $(20 \mathrm{~mL})$ was added to OMS-2, and additional deionized water $(6 \mathrm{~mL})$ was added to wash down the sides of the flask. Then the flask was submerged into an ultrasound bath for $3 \mathrm{~h}$ at room temperature and stirred for further $20 \mathrm{~h}$ at room temperature. After that, the water was distilled under reduced pressure on a rotary evaporator at $80{ }^{\circ} \mathrm{C}$ for more than $2 \mathrm{~h}$. Finally, the black powder was dried into an oven at $110{ }^{\circ} \mathrm{C}$ for 4 $\mathrm{h}$ followed by calcination at $350{ }^{\circ} \mathrm{C}$ for $2 \mathrm{~h}$.

\subsection{Typical Procedure for the Synthesis of Dihydrotriazines}

Cu/OMS-2 (10 mg, $0.25 \mathrm{~mol} \%)$, benzyl alcohol (2 mmol), $\mathrm{N}$-arylamidine $(0.5 \mathrm{mmol})$, toluene $(2 \mathrm{~mL})$ were added to a flask with a bar. The flask was stirred at $90{ }^{\circ} \mathrm{C}$ for $20 \mathrm{~h}$ under air. After cooling to room temperature, the mixture was diluted with ethyl acetate and filtered. The filtrate was removed under reduced pressure to get the crude product, which was further purified by silica gel chromatography (petroleum/ethyl acetate $=40 / 1-50 / 1$ as eluent) to yield corresponding product. The identity and purity of the products were confirmed by ${ }^{1} \mathrm{H},{ }^{13} \mathrm{C}$ NMR spectroscopic and HRMS analysis.

\section{Results and discussion}

Firstly, elemental analysis of the catalyst by atomic absorption spectrometry (AAS) indicated that the quantity of $\mathrm{Cu}$ in the sample was 0.5 wt.\%. Next, X-ray diffraction (XRD) was used to analysis OMS-2, $\mathrm{Cu} / \mathrm{OMS}-2$ and the OMS-2 material synthesized by conventional reflux method (designated as OMS-2-Re).[15] The patterns in Figure 1 demonstrated that the diffraction peaks of OMS-2 and Cu/OMS-2 were the same as that of OMS-2-Re, which means OMS-2 was formed 
successfully using TBHP as reductant and its supported catalyst was also typical cryptomelane materials (JCPDS file \#29-1020).[15] No signals due to copper metal (cluster) or copper oxide were observed, which suggests that the copper oxide was low loading and highly dispersed on OMS-2. Finally, OMS-2 and Cu/OMS-2 were characterized by transmission electron microscope (TEM) and scanning electron microscope (SEM). It was found that OMS-2 was very uniform in length and had a typical uniformly nano-rod morphology (Fig. 2), which was in agreement with the previous research.[15] Moreover, the width of the OMS-2 nanofibers was in 5-16 $\mathrm{nm}$ range based on the counting of 180 particles (Fig. S3, see ESI). For Cu/OMS-2, the catalyst remained the fibers or needlelike morphology (Fig. 3) (For more characterization of OMS-2 and Cu/OMS-2, see ESI).

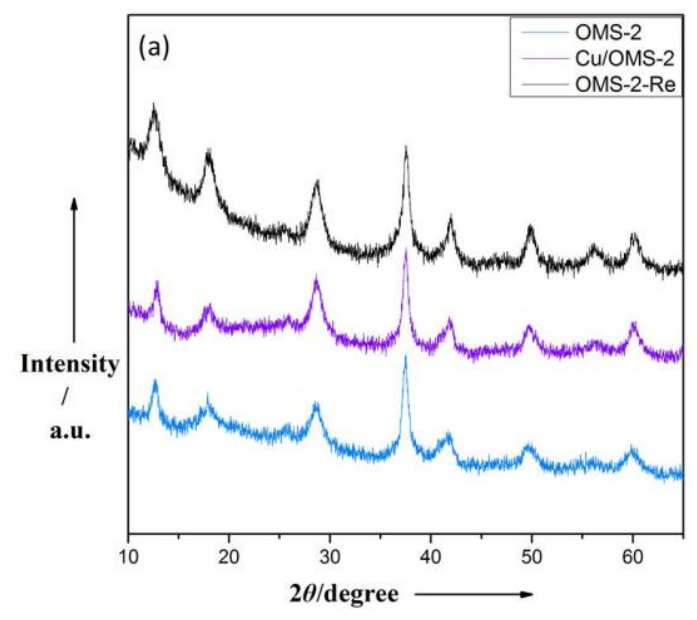

Figure 1. The XRD patterns of OMS-2, Cu/OMS-2 and OMS-2-Re

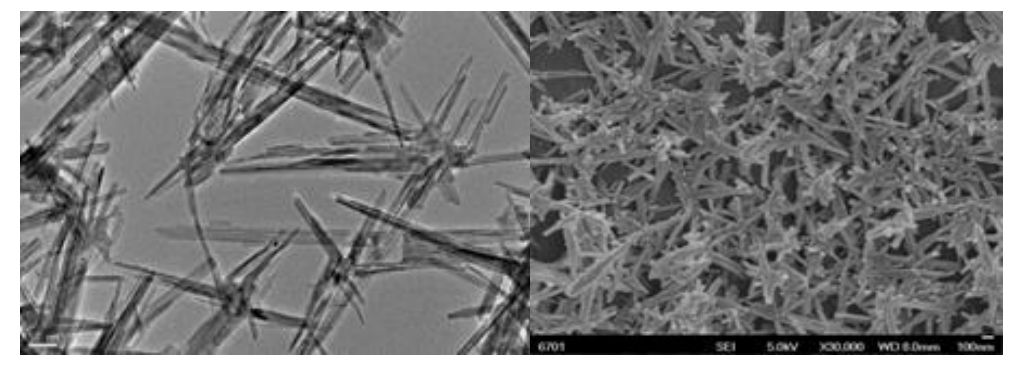

Figure 2. The TEM and SEM images of OMS-2 


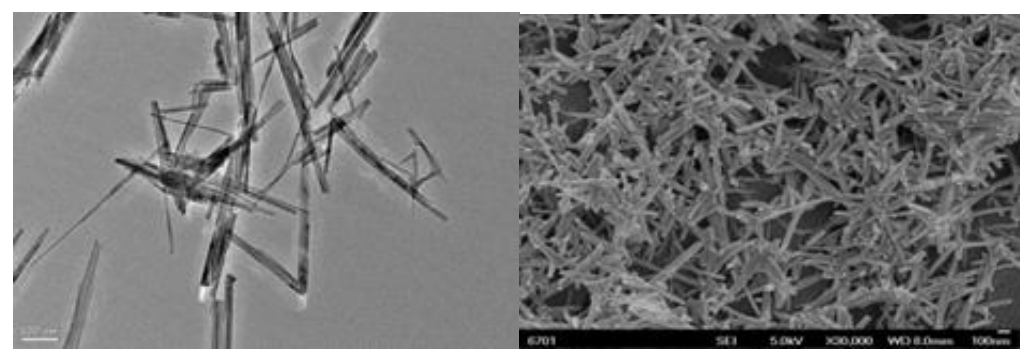

Figure 3. The TEM and SEM images of $\mathrm{Cu} / \mathrm{OMS}-2$.

According to previous reports, it is known OMS-2 has excellent redox ability.[11,16,17,19] Therefore, we were supposed to direct use alcohol as starting material which transforms in situ to aldehyde and then reacts with two molecules of amidine to offer cyclized product 1,2-dihydro-1,3,5-triazine. A screening was conducted to optimize the reaction conditions by reacting benzyl alcohol (1a) and $\mathrm{N}$-arylamidine (2a). Initially, background reactions were run in toluene under air at $90{ }^{\circ} \mathrm{C}$, which demonstrates the reaction did not occur without catalyst or only using support OMS-2 as catalyst (Table 1, entries 1 and 2). Catalytic amounts of commercial bulk $\mathrm{CuO}$ and nano-sized $\mathrm{CuO}$ could not catalyze the reaction under the standard conditions as well (Table 1, entries 3 and 4). Similarly, a physical mixture of $\mathrm{CuO}$ and OMS-2 did not show any catalytic activity in the reaction (Table 1 , entry 5).To our delight, the addition of $\mathrm{Cu} / \mathrm{OMS}-2$ (Cu: $0.25 \mathrm{~mol} \%$ ) led to the desired product 1,2-dihydro-1,3,5-triazine (3a) in 91\% isolated yield while another cyclized product 4a was not observed (entry 6). Compared with $\mathrm{Cu} /$ ligand system of previous research,[25] it is believed that OMS-2 enhanced the oxidative ability of supported $\mathrm{Cu}$ for converting benzyl alcohol into benzaldehyde, next promoted nucleophilic attack ability of amidine to carbonyl group, changed the reaction pathway by enhancing nucleophilicity of another molecule of amidine for the eventual oxidative cyclization as well (vide infra). Furthermore, above results indicate highly dispersed copper species on OMS-2 might play an important role during the reaction. To confirm the reaction is an oxidative process, the reaction was run under $\mathrm{N}_{2}$ and it did not proceed, which means the oxygen in air played a role as terminal oxidant (entry 7). After the reaction under $\mathrm{N}_{2}$, the XRD was used to analyze the catalyst, which 
shows OMS-2 changed to a $\mathrm{Mn}_{3} \mathrm{O}_{4}$ phase (JCPDS card no. 24-0734, Fig. S6, see ESI). Two other OMS-2-based catalysts, acid-modified $\mathrm{Cu} / \mathrm{H}-\mathrm{OMS}-2[12] \quad(10 \mathrm{mg}, \quad \mathrm{Cu}: \quad 0.5 \quad \mathrm{wt} \%)$ and hydroxide $\mathrm{Cu}(\mathrm{OH})_{\mathrm{x}} / \mathrm{OMS}-2[20](10 \mathrm{mg}, \mathrm{Cu}: 1.3 \mathrm{wt} \%)$, were used to improve the reaction, but they failed to show good selectivity (entries 8 and 9). Consequently, the optimal reaction conditions for the synthesis of 1,2-dehydro-1,3,5-triazine can be indicated in entry 5 of Table 1 (For more optimizations and reutilization of catalyst, see ESI).

Table 1. Optimization of the reaction conditions ${ }^{\mathrm{a}}$

\begin{tabular}{|c|c|c|c|c|c|}
\hline \multirow[t]{2}{*}{ entry } & \multirow[t]{2}{*}{ catalyst } & \multirow[t]{2}{*}{$\mathbf{1 a}(\mathrm{mmol})$} & \multirow[t]{2}{*}{ solvent } & \multicolumn{2}{|c|}{ yield $(\%)^{\mathrm{b}}$} \\
\hline & & & & $\mathbf{3 a}$ & $4 \mathbf{a}$ \\
\hline 1 & - & 2 & toluene & 0 & 0 \\
\hline 2 & OMS-2 & 2 & toluene & 0 & 0 \\
\hline 3 & $\mathrm{CuO}(10 \mathrm{~mol} \%)$ & 2 & toluene & 0 & 0 \\
\hline 4 & Nano-CuO (10 mol\%) & 2 & toluene & 0 & 0 \\
\hline $5^{c}$ & $\mathrm{CuO}+\mathrm{OMS}-2$ & 2 & toluene & 0 & 0 \\
\hline $6^{\mathrm{d}}$ & Cu/OMS-2 & 2 & toluene & $95(91)$ & $\mathbf{0}$ \\
\hline $7^{\mathrm{e}}$ & $\mathrm{Cu} / \mathrm{OMS}-2$ & 2 & toluene & 0 & 0 \\
\hline 8 & $\mathrm{Cu} / \mathrm{H}-\mathrm{OMS}-2$ & 2 & toluene & 76 & 19 \\
\hline 9 & $\mathrm{Cu}(\mathrm{OH})_{\mathrm{x}} / \mathrm{OMS}-2$ & 2 & toluene & 52 & 24 \\
\hline
\end{tabular}

${ }^{\text {a }}$ Reaction conditions: 1a, 2a $(0.5 \mathrm{mmol})$, catalyst $(10 \mathrm{mg})$, solvent $(2 \mathrm{~mL})$, air, $90{ }^{\circ} \mathrm{C}, 20 \mathrm{~h}$.

${ }^{\mathrm{b}} \mathrm{NMR}$ yield using $\mathrm{CH}_{2} \mathrm{Br}_{2}$ an internal standard and isolated yield is given in parenthesis.

${ }^{\mathrm{C}} 10 \mathrm{~mol} \%$ of $\mathrm{CuO}$ and $10 \mathrm{mg}$ OMS-2 were used.

${ }^{\mathrm{d}} 10 \mathrm{mg}$ of Cu/OMS-2 (Cu: $\left.0.5 \mathrm{wt} \%\right)$ was used.

${ }^{\mathrm{e}}$ Under $\mathrm{N}_{2}$.

With the optimal conditions in hand, we continued to investigate the scope of the reactions by employing a variety of alcohols with 
N-phenylbenzimidamide (Scheme 3). Gratifyingly, benzyl alcohols with electron-withdrawing and electron-donating substituted groups reacted with N-phenylbenzimidamide very well and selectively furnished corresponding products $\mathbf{3 a - 3 k}$ in moderate to good yields. However, we found that the steric effect influenced the reaction significantly, such as benzyl alcohol with substituent at the meta-position, and the substrate showed the poor reactivity in the reaction under the standard conditions (Scheme 3, 3d). However, disubstituted benzyl alcohols offered corresponding products in good yields probably because substituents at para-positions balanced electron density of the benzene ring and activated the benzyl alcohols (Scheme 3, 3h and 3i). Benzyl alcohol with sensitive substituent $-\mathrm{NO}_{2}$ was also compatible with the reaction conditions, although the desired product $\mathbf{3 l}$ was isolated in a low yield of $37 \%$. Pleasingly, trans-cinnamyl alcohol was a good substrate in the reaction and $56 \%$ yield of desired product $3 \mathrm{~m}$ was isolated without observation of cyclized product 1,2,4-trisubstituted-1H-imidazole-5-carbaldehyde.[26] Furthermore, $\mathrm{Cu} / \mathrm{OMS}-2 / \mathrm{O}_{2}$ system was able to oxidize heteroaromatic alcohols, like pyridin-2-ylmethanol and thiophen-2-ylmethanol, and convert them with $\mathrm{N}$-phenylbenzimidamide into the corresponding products selectively in moderate yields (Scheme 3, 3n and 3o). Interestingly, not only aromatic alcohols were suited for the reactions, but aliphatic alcohols also worked smoothly and provided the corresponding products in excellent yields (Scheme 3, 3p and 3q).
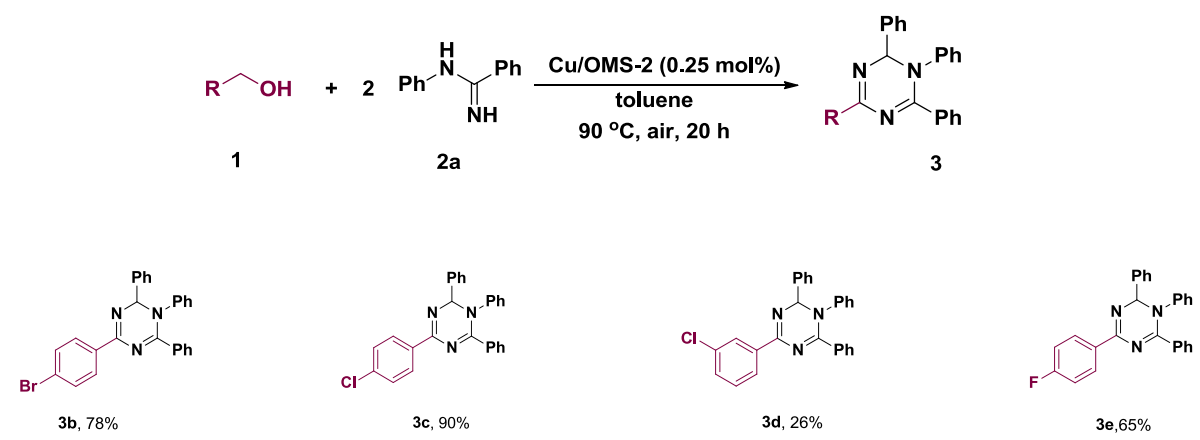

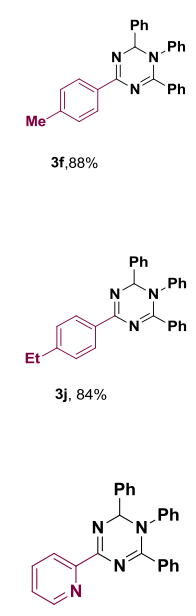

3 , $53 \%$
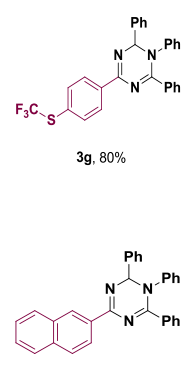

$3 \mathbf{k}, 91 \%$

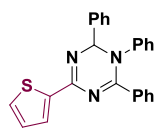

$30,62 \%$
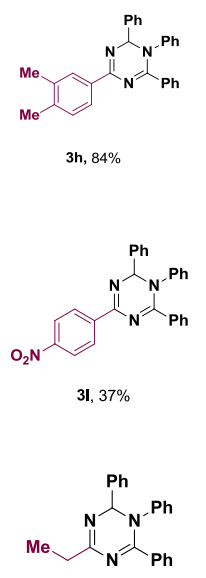

$3 p, 95 \%$
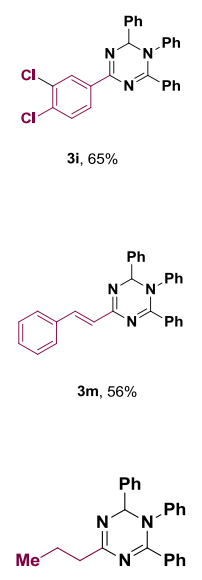

$3 q, 90 \%$

Scheme 3. Synthesis of 1,2-dihydro-1,3,5-triazines using different alcohols. Reaction conditions: 1a (2 mmol), $2 \mathbf{a}(0.5 \mathrm{mmol}), \mathrm{Cu} / \mathrm{OMS}-2$ $(10 \mathrm{mg})$, toluene $(2 \mathrm{~mL})$, air, $90^{\circ} \mathrm{C}, 20 \mathrm{~h}$, isolated yields.

Following these encouraging results for a wide range of alcohols, we examined the scope of the reactions with a variety of N-phenylbenzimidamide (Scheme 4). Under the optimal reaction conditions, many N-phenylbenzimidamides with different substituents could react with benzyl alcohols smoothly and offered desired products with moderate to good yields. In particular, electron-rich $\mathrm{N}$-phenylbenzimidamides provided slightly higher yields of products than electron-poor ones did. Unfortunately, the reaction did not work with aliphatic amidines. We believe that the formation of imine from aldehydes and aliphatic amidines might be difficult under the standard reaction conditions.
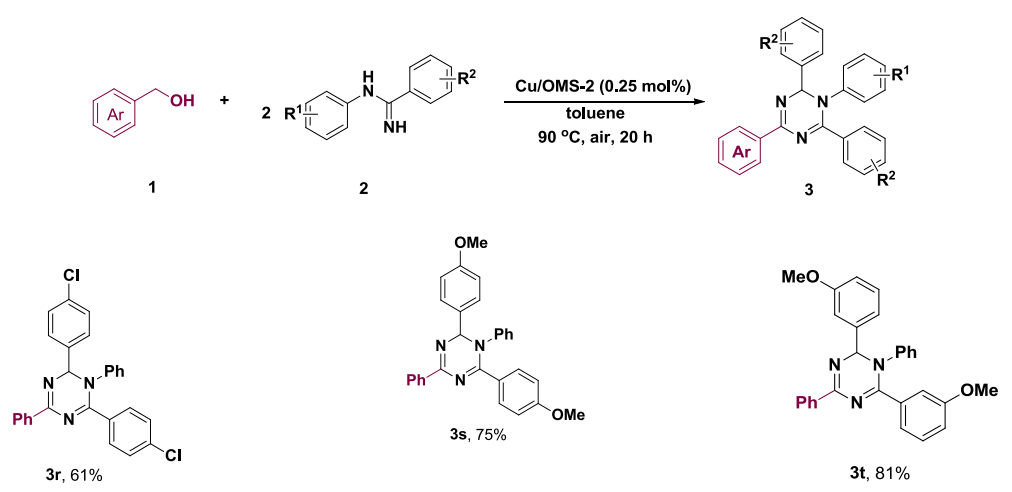

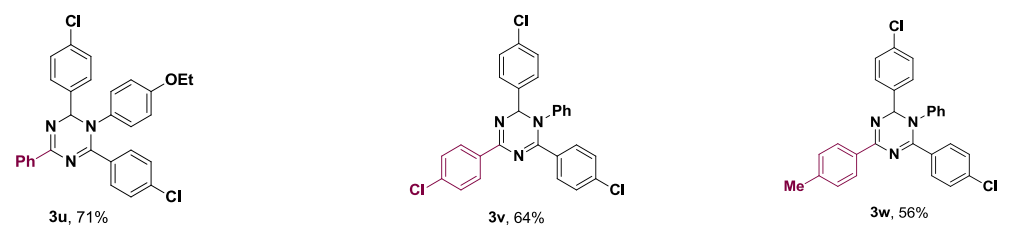

Scheme 4. Synthesis of 1,2-dihydro-1,3,5-triazines using benzyl alcohols and different $\mathrm{N}$-arylamidines. Reaction conditions: 1a (2 mmol), 2a (0.5 $\mathrm{mmol}), \mathrm{Cu} / \mathrm{OMS}-2(10 \mathrm{mg})$, toluene $(2 \mathrm{~mL})$, air, $90{ }^{\circ} \mathrm{C}, 20 \mathrm{~h}$, isolated yields.

To gain insight into the reaction mechanism, control experiments were conducted (Scheme 5). Firstly, it was found that $\mathrm{Cu} / \mathrm{OMS}-2$ was efficient for the oxidation of alcohol and OMS-2 oxidized alcohol to aldehyde in relatively low yield in the presence of air (Scheme 5, a). Next, we direct employed aldehyde as the substrate reacting with $\mathrm{N}$-arylamidine under the standard reaction conditions, the high yield of 1,2-dihydro-1,3,5-triazine (3a) was obtained (Scheme 5, b). Furthermore, the reaction between aldehyde and $\mathrm{N}$-arylamidine could perform at even low temperature, like $70{ }^{\circ} \mathrm{C}$, although the yield of desired product was low (Scheme 5, b). The above experimental results suggested that aldehyde was first formed via the oxidation of alcohol in situ and further participated in the reaction with $\mathrm{N}$-arylamidine. From the previous work of OMS-2-catalyzed imines synthesis,[28] it is known that OMS-2 materials were able to use as efficient catalysts for the synthesis of imines via $\mathrm{C}-\mathrm{N}$ bond formation between alcohols and amines. Thus, we proposed intermediate A (in Scheme 6) might be the next intermediate and tried to isolate it from condensation of aldehyde and $\mathrm{N}$-arylamidine for the further understanding of the reaction mechanism. However, it was failed to isolate intermediate $\mathbf{A}$ even at low reaction temperature perhaps because it is too unstable to isolate or it quickly transforms in the reaction. Based on our experimental results and previous research of OMS-2-based materials catalyzed oxidations,[12e, 12i] a possible reaction pathway is proposed in Scheme 6. Initially, benzyl alcohol is oxidized in situ by $\mathrm{Cu} / \mathrm{OMS}-2$ via multistep oxidation using $\mathrm{O}_{2}$ as the terminal oxidant to 
benzaldehyde.[27] Then, the imine intermediate $\mathbf{A}$ is formed between benzaldehyde and $\mathrm{N}$-arylamidine catalyzed by $\mathrm{Cu} / \mathrm{OMS}-2$ with the elimination of $\mathrm{H}_{2} \mathrm{O}$.[28] Notably, the intermediate A led to quinazoline under $\mathrm{Cu} /$ ligand $/ \mathrm{O}_{2}$ system,[25] while this intra-molecular cyclized compound was not detected under $\mathrm{Cu} / \mathrm{OMS}-2 / \mathrm{O}_{2}$ system. It is believed that another molecule of $\mathrm{N}$-arylamidine, which possesses stronger nucleophilicity caused by the assistance of OMS-2, attacks the imine intermediate A via inter-molecular nucleophilic addition of amino group to generate intermediate $\mathbf{B}$ after proton transfer. Next, the intra-molecular nucleophilic addition of amino group on $\mathbf{B}$ occurs quickly to form intermediate $\mathbf{C}$. The symmetrical dihydrotriazine $\mathbf{D}$ is formed after the elimination of aniline that is detected by GCMS. Eventually, the desired product 1,2-dihydro-1,3,5-triazine is obtained after tautomerization of $\mathbf{D}$.
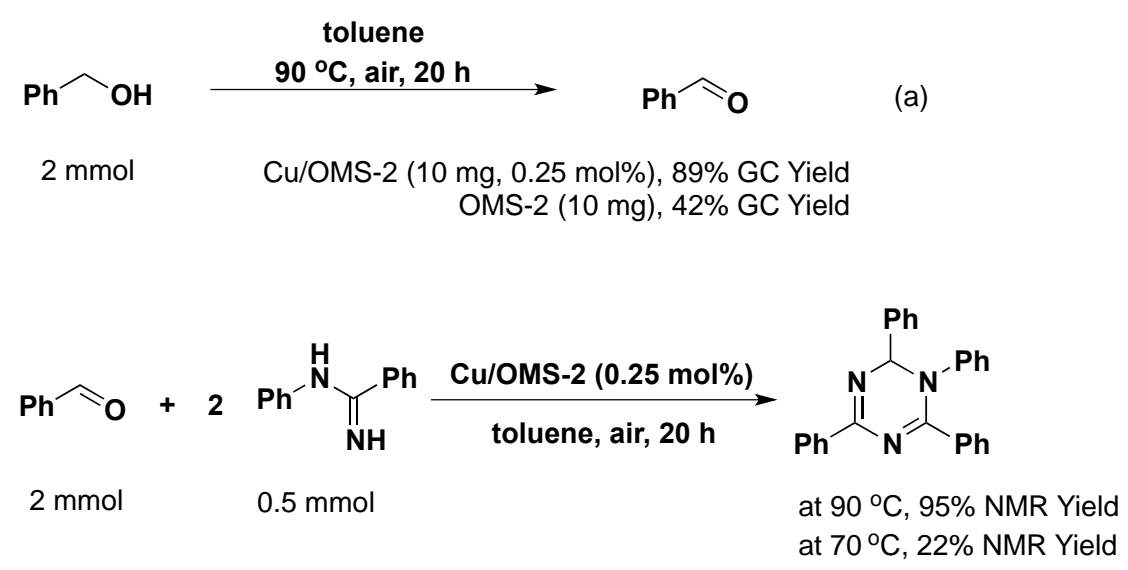

Scheme 5. Control experiments.

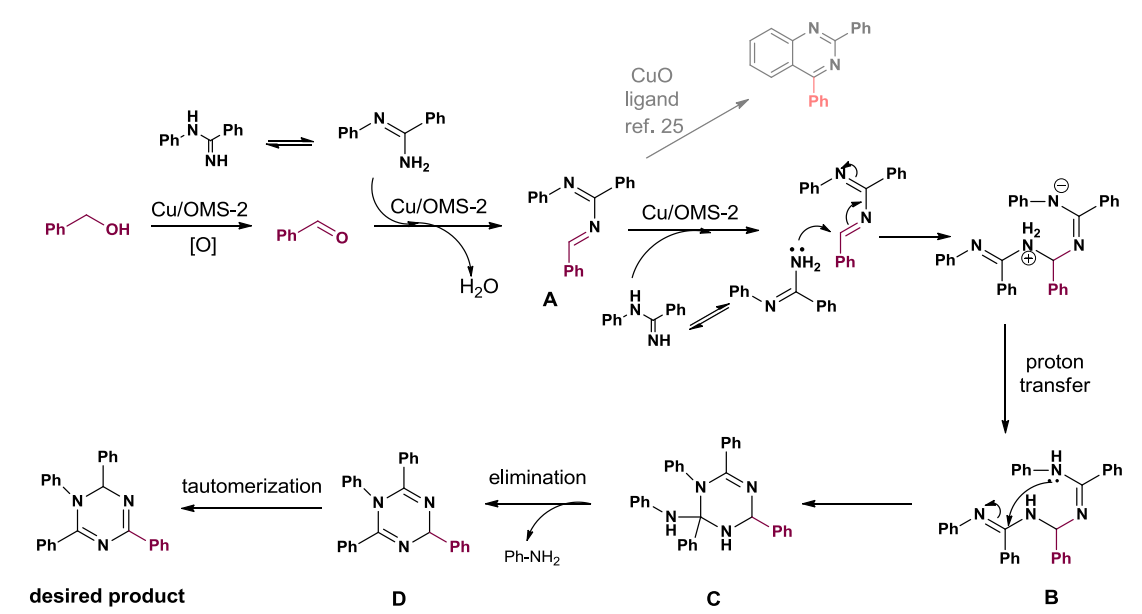

Scheme 6. Proposed mechanism.

\section{Conclusion}


In conclusion, we have synthesized OMS-2 through the reduction of $\mathrm{KMnO}_{4}$ by TBHP and used it as support and ETM to prepare supported catalyst $\mathrm{Cu} / \mathrm{OMS}-2$ which could efficiently catalyze the oxidative synthesis of 1,2-dihydro-1,3,5-triazines directly from alcohols and $\mathrm{N}$-arylamidines. The catalytic system relying on the combination of $\mathrm{Cu}$ and OMS-2 for multistep oxidation under a low-energy pathway tolerates various substrates and offers desired products in good yields with air as the terminal oxidant. We are currently focusing on further expanding the application of the catalytic system.

\section{Acknowledgements}

We gratefully acknowledge the National Natural Science Foundation of China (Grant Nos. 21403256, 21573261, 21372102) and the Suzhou Industrial Technology and Innovation Project (Grant No. SYG201531) and the Project of National Science Foundation of Gansu Province (No. 1208RJZA266).

\section{Appendix A. Supplementary data}

Supplementary data to this article can be found online at http://

\section{References}

[1] J. E. Bäckvall, Modern Oxidation Methods, VCH-Wiley, Weinheim, 2004.

[2] J. Piera, J. E. Bäckvall, Angew. Chem. Int. Ed. 47 (2008) 3506-3523.

[3] B. P. Babu, X. Meng, J. E. Bäckvall, Chem. Eur. J.19 (2013) 4140-4145.

[4] X. Meng, C. Li, B. Han, T. Wang, B. Chen, Tetrahedron 66 (2010) 4029-4013.

[5] N. Gigant, J. E. Bäckvall, Org. Lett. 16 (2014) 1664-1667

[6] N. Gigant, J. E. Bäckvall, Org. Lett. 16 (2014) 4432-4435.

[7] N. Gigant, J. E. Bäckvall, Chem. Eur. J. 19 (2013) 10799-10803.

[8] L. Ta, A. Axelsson, H. Sundén, Green Chem. 18 (2016) 686-690.

[9] K. M. H. Nguyen, M. Largeron, Chem. Eur. J. 21 (2015) 
12606-12610.

[10] K. M. H. Nguyen, M. Largeron, Eur. J. Org. Chem. (2016) 1025-1032.

[11] X. Meng, C. Yu, G. Chen, P. Zhao, Catal. Sci. Technol. 2015, 5, 372-379.

[12] X. Meng, J. Zhang, B. Chen, Z. Jing, P. Zhao, Catal. Sci. Technol. 6 (2016) 890-896.

[13] J. Zhang, X. Meng, C. Yu, G. Chen, P. Zhao, RSC Adv. 5 (2015) 87221-87227.

[14] S. L. Suib, Acc. Chem. Res. 41 (2008) 479-487.

[15] S. L. Suib, J. Mater. Chem. 18 (2008) 1623-1631.

[16] Y. F. Shen, R. P. Zerger, R. N. DeGuzman, S. L. Suib, L. McCurdy, D. I. Potter, C. L. O'Young, Science 260 (1993) 511-515.

[17] K. Yamaguchi, H. Kobayashi, Y. Wang, T. Oishi, Y. Ogasawara, N. Mizuno, Catal. Sci. Technol. 3 (2013) 318-327.

[18] X. Jin, K. Yamaguchi, N. Mizuno, RSC Adv. 4 (2014) 34712-34715.

[19] X. Meng, J. Zhang, G. Chen, B. Chen, P. Zhao, Catal. Comm. 69 (2015) 239-242.

[20] T. Oishi, K. Yamaguchi, N. Mizuno, ACS Catal. 1 (2011) 1351-1354.

[21] V. Štrukil, I. Đilović, D. Matković-Čalogović, J. Saame, I. Leito, P. Šket, J. Plavec, M. Eckert-Maksić, New J. Chem. 36 (2012) 86-96.

[22] C. J. Peake, T. G. Cullen, A. C. Lew, Patent US, 5,300,503, 1994.

[23] N. Heße, R. Fröhlich, B. Wibbeling, E.-U. Würthwein, Eur. J. Org. Chem. (2006) 3923-3937.

[24] G. Lowe, C. Carr, R. Quarrell, Chem. Commun. (2001) 737-738.

[25] W. Zhang, F. Guo, F. Wang, N. Zhao, L. Liu, J. Li, Z. Wang, Org. Biomol. Chem. 12 (2014) 5752-5756.

[26] Y. Li, Y. Fu, C. Ren, D. Tang, P. Wu, X. Meng, B. Chen, Org. Chem. Front. 2 (2015) 1632-1636. 
[27] Y. C. Son, V. D. Makwana, A. R. Howell, S. L. Suib, Angew. Chem. Int. Ed. 40 (2001) 4280-4283.

[28] S. Sithambaram, R. Kumar, Y.-C. Son, S. L. Suib, J. Catal. 253 (2008) 269-277. 


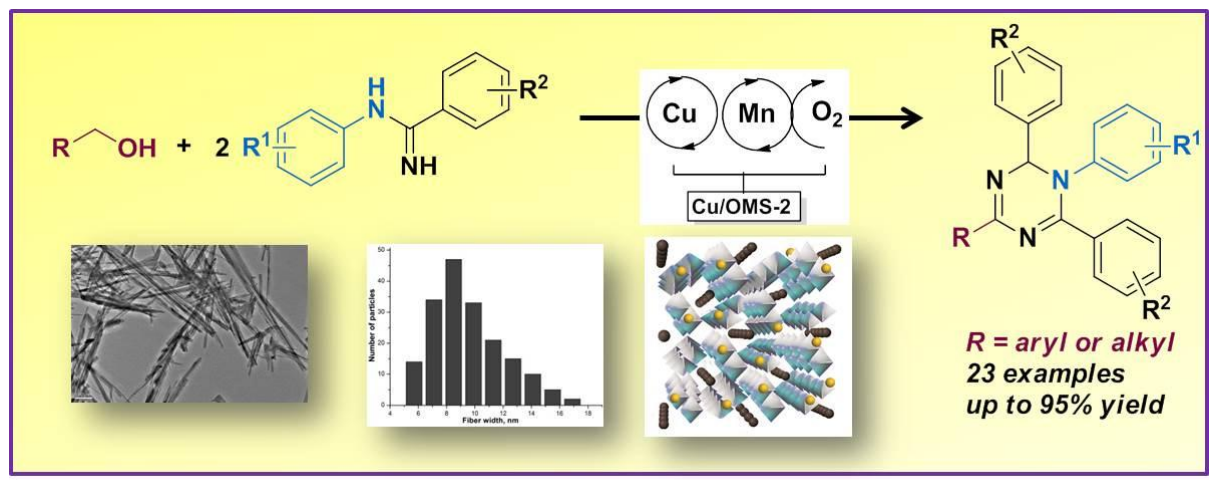

